\title{
OBJEK-OBJEK DALAM RITUAL PENANGKAL HUJAN
}

\author{
Imaniar Yordan Christy \\ SMP KRISTEN YSKI Semarang \\ ImaniarYch@gmail.com
}

\begin{abstract}
Rain prevention is a ritual that many people do in some areas in Indonesia. In addition to Indonesia, this ritual is also conducted in Japan. The ritual uses various objects. This study discusses the meaning of rain-prevention rituals in some regions of Indonesia and in Japan, and the objects used for the rituals. The purpose of this study is to discover the meaning of rain-prevention rituals, to discover the symbols of ritual objects, and to discover the rainpreventing rituals in some areas in Indonesia and in Japan. The method of analysis used is the method of cultural research.
\end{abstract}

Key words: ritual, rain-prevention, ritual object

\section{Pendahuluan}

Cuaca adalah faktor alam yang sangat berpengaruh bagi masyarakat dalam menjalankan aktivitasnya. Khususnya bagi masyarakat yang tinggal di negara dua musim yaitu musim kemarau dan musim penghujan. Cuaca menjadi pertimbangan untuk melaksanakan suatu acara atau kegiatan. Di Indonesia ada sebagian masyarakat yang percaya bahwa jika hujan turun pada saat mereka mengadakan hajatan (pesta pernikahan/khitanan) maka hujan tersebut di anggap sebagai berkah. Namun, ada juga sebagian masyarakat lain yang sangat berharap cuaca cerah ketika mereka menyelenggarakan hajatan. Selain acara pesta, cuaca juga berpengaruh bagi petani dan nelayan. Hujan adalah hal yang sangat ditunggu-tunggu oleh para petani untuk menam padi. Sedangkan bagi nelayan cuaca yang cerah akan sangat membantu mereka karena aman untuk pergi ke laut. Hal ini menyebabkan ritual panggil dan tolak hujan terjadi di beberapa daerah di Indonesia.

Ritual panggil dan tolak hujan ini ternyata tidak hanya dikenal oleh masyarakat Indonesia, tetapi juga mancanegara. Media mencatat ritual tolak hujan terjadi pada pembukaan Olimpiade Beijing tahun 2008. Begitu juga dengan ritual panggil hujan terjadi di Bihar India yaitu para petani bertelanjang dada untuk memanggil hujan.

< http://www.antaranews.com>

Salah satu negara yang masih menggunakan benda atau objek untuk menolak turunnya hujan selain di Indonesia adalah Jepang. Bahkan ritual ini tidak hanya terkam di film-film untuk orang dewasa saja namun di film kartun anak-anak berjudul Doraemon benda atau objek ini sering dimunculkan ketika tokoh nobita ingin agar cuaca cerah. Hal ini menjadi menjadi sangat menarik mengingat Jepang adalah negara maju namun kepercayaannya terhadap benda atau objek ritual ini tetap terjaga hingga di tahun 2017 ini.

Dalam pelaksanaan ritual panggil maupun tolak hujan dibutuhkan benda/objek ritual yang harus disiapkan. Jika benda/objek tersebut tidak lengkap, masyarakat percaya bahwa ritual tersebut tidak akan berhasil. Hal ini dilakukan agar makhluk-makhluk halus di atas kekuatan manusia tidak mengganggu. Dengan pemberian makan secara simbolik kepada roh halus, diharapkan roh tersebut akan jinak, dan mau membantu hidup manusia (Endaswara, 2003b: 195) yaitu membatu permintaan manusia untuk memanggil atau menolak hujan.

Kepercayaan merupakan faktor yang paling menentukan berhasil atau 
tidaknya ritual tersebut. Kepercayaan terhadap benda atau objek ritual inilah yang penulis angkat dalam studi ini. Bagaimana makna benda/objek dalam ritual penangkal hujan dan bagaimana tradisi penangkal hujan di beberapa daerah di Indonesia dan Jepang?

Kebudayaan adalah serangkaian kegiatan yang dilakukan manusia sebagai bentuk hasil cipta, rasa, dan karsa yang berguna untuk mencapai pemenuhan kehidupan manusia (Widyastuti, 2013: 2). Ritual adalah bagian dari kebudayaan. Bagi masyarakat Jawa dan Bali khususnya ritual menjadi hal yang begitu penting sebagai wujud pnghormatan kepada roh yang mereka hormati.

Jawa merupakan sebuah pulau yang masih memegang prinsip tentang adanya adat atau tradisi yang telah diwariskan oleh nenek moyang pada zaman dahulu, karena masyarakat Jawa merupakan suatu kesatuan masyarakat yang diikat oleh norma-norma hidup karena sejarah, tradisi maupun agama (Darori, 2000: 4).

Kepercayaan terhadap roh-roh halus dan dunia supranatural tidak bisa dihilangkan dari pemikiran masyarakat. Kepercayaan itu terjadi secara turun temurun. Para sesepuh yang dianggap sebagai orang yang bisa berhubungan dengan alam dunia lain menjadi orang yang sangat dihormati dan selalu dimintai pendapatnya ketika masyarakat membutuhkan bantuan atas segala permaslahan mereka. Begitu juga ketika orang akan mengadakan suatu acara dan mengharapkan cuaca cerah, maka mereka juga akan mendatangi seorang pinisepuh yang dianggap memiliki kesaktian memanggil atau menolak hujan. Biasanya masyarakat memanggilnya sebagai pawang hujan.

Penelitian ini termasuk dalam kategori penelitian Antopologi Budaya (Harsojo, 1982: 182), karena di dalam penulisannya menggunakan pendekatan Adaptasi Kultural. Sebagaimana telah disebutkan bahwa Antropologi budaya bermakna pengetahuan yang berkaitan dengan manusia (masyarakat) serta hubungannya dengan kebudayaan yang berkembang (Koentjaraningrat, 2002: 64). Studi pustaka adalah cara pengumpulan data melalui buku-buku yang relevan dengan permasalahan yang diteliti, melalui peninggalan tertulis berupa arsip-arsip dan termasuk juga bahan tentang pendapat, teori, dalil dan sebagainya yang berhubungan dengan masalah yang diselidiki (Nawawi, 1990: 133).

Dalam penelitian ini metode yang digunakan adalah metode penelitian budaya dengan jenis penelitian kualitatif. Tujuan dari metode kualitatif ialah supaya penulis dapat mengenal secara mendalam tentang lingkungan penelitian dengan menggunakan analisis deskriptif, peneliti berusaha menemukan bukti yang dialami dalam penalaran formal atau analitik. Hal ini bertujuan untuk mempertahankan bentuk-bentuk perilaku manusia dengan ciri khas masing-masing individu (Mulyana, 1999: 150).

\section{Makna Tradisi Penangkal Hujan}

Dalam buku yang diberi judul Drawings of Balinese Sorcery, Hooykaas (1980: 45) mengklasifikasikan panerangan tolak hujan dan pangujanan panggil hujan dalam kategori keeping watch, change and defence penjaga, pengubah, dan bela diri. Tolak hujan dipadankan dengan the art of clearing the sky ilmu membersihkan langit, sedangkan panggil hujan dipadankan dengan the art of making wind and rain ilmu membuat angin dan hujan. Mantra tolak dan panggil hujan merupakan gabungan antara mantra dan sarana teks. Sarana yang dimaksud mencakup sajen dan rerajahan gambar yang biasanya terdiri atas huruf atau figur.

Untuk fungsi menolak hujan dapat digunakan gambar figur Bhatara Yama dewa penguasa surga yang mengadili roh setelah melewati batas akhir hidup, Singambara singa terbang ataupun rerajahan gambar berbentuk lingkaran, persegi dan bentuk lainnya. Pada teks pangujanan mengundang hujan dapat 
digunakan rajahan Bhatara Guru, Bhatara Wisnu, Hanoman kera putih, atau Bhima tokoh sakti dari Pandawa lima. Figur lain yang sering dimunculkan adalah Demung Dodokan dewa naga laut, Kalarau, Yuyu kepiting, Kodok kodok, Dewa Langit Arsa Telu dewa langit berkepala tiga, atau Naga Nguyup Matanai naga menelan matahari. Hooykaas menyatakan bahwa praktik tolak hujan dapat digunakan sebagai proteksi pertunjukan wayang kulit.

\section{Benda atau Objek dalam Penangkal Hujan \\ 3.1 Arti Simbol Benda atau Objek dalam Penangkal Hujan}

Ritual penangkal hujan membutuhkan sesaji. Sesaji yang paling penting adalah tumpeng. Tumpeng ini disebut tumpeng robyong yang mengandung simbol budaya. Menurut Endaswara (2014: 254), simbolsimbol itu dibuat didasarkan pada analogi (otak-atik mathuk) dan olah nalar pelaku mistik. Ubarampe termaksud, mampu menggambarkan perjalanan hidup manusia dari "ada" menjadi "tiada," yakni sebagai berikut.

1. Telur, lambang wiji dadi (benih) terjadinya manusia.

2. Bumbu megana (gudangan): merupakan lukisan bakal (embrio) hidup manusia.

3. Cambah: benih dan bakal manusia yang akan selalu tumbuh.

4. Kacang panjang: dalam kehidupan semestinya manusia berfikir panjang (nalar kang mulur) dan jangan memiliki pemikiran picik (mulur mungkrete nalar pating saluwir), sehingga dapat menanggapi segala hal dengan kesadaran.

5. Tomat: kesadaran itu akan menimbulkan perbuatan yang gemar maksiat berupaya menjadi jalma limpet sepraprat tamat.

6. Brambang: perbuatan yang selalu dengan pertimbangan.

7. Kangkung: manusia semacam itu tergolong manusia linangkung (tingkat tinggi).
8. Bayem: karenanya bukan mustahil kalau hidupnya jadi ayem tentrem.

9. Lombok abang: akhirnya akan muncul keberanian dan tekad untuk manunggal dengan Tuhan.

10. Ingkung: Cita-cita manunggal itu dilakukan melalui manekung.

\subsection{Ritual Penangkal Hujan}

Ritual dipercaya bisa menjadi alat untuk menguatkan maksud menunda turunnya hujan. Melakukan ritual dengan pasa mutih, berpuasa dengan hanya makan nasi tanpa garam dan minum air putih, selama tiga hari. Selain pasa mutih, sebelum hajatan diadakan, pawang hujan akan datang ke tempat itu untuk memasang sepasang janur. Janur ini diikat pada tiang yang menjadi pusat acara.

Jika acaranya menggunakan panggung, maka janur diikat di dua tiang panggung. Jika acara dilakukan dalam gedung, pawang hujan akan mengikat sepasang janur di pintu masuk, kanan dan kiri. Kadang-kadang karena alasan teknis, mendung yang sudah penuh titik air hujan tak bisa disibakkan. Kalau sudah dalam kondisi tersebut, maka justru akan diturunkan hujan sebelum acara. Jadi ketika acara dimulai, langit sudah bersih (Sudikan, 2001).

Bisa jadi ada banyak pawang hujan yang diminta bantuan untuk 'mengamankan' daerah tertentu. Jika sudah begini akan terjadi 'perang' antar pawang. Kekuatan pawang yang menentukan siapa yang bisa memindahkan hujan ke daerah lain. Biasanya diambil kesepakatan untuk mengalihkan hujan ke daerah yang sama.

Satu-satunya alat yang digunakan adalah sapu lidi yang dipasang terbalik. Pada ujung sapu lidi ini ditancapkan bawang merah, bawang putih, dan cabai. Menurut Joko Hari Nugroho, ini kebiasaan warga Magetan ketika melangsungkan pernikahan. "Karena biasanya mereka menyiapkan masakan sendiri dalam jumlah besar dan memakai pekarangan terbuka, maka sapu lidi ini sebagai sarana untuk menahan hujan agar acara memasak tetap 
lancar," kata Joko Hari Nugroho dalam wawancara tanggal 19 Januari 2010. Karena urusannya dengan dapur maka perlambang yang digunakan dalam alat juga berhubungan dengan isi dapur. <http://regional.liputan6.com/read/243821 6/begini-cara-kerja-pawang-hujanmengendalikan-hujan>

Ritual atau laku mistik menurut Saputra (2007) adalah proses ritual yang dilakukan untuk mendapatkan kekuatan gaib. Dalam konsep Islam (santri), laku mistik dapat dilakukan dengan salat lima waktu secara khusyuk dan memperbanyak dzikir. Sedangkan dalam konteks tradisi atau abangan dapa dilakukan dengan cara puasa, semedi, dan lek-lekan. Laku mistik tersebut sebenarnya diperlukan oleh seseorang sebagai perantara untuk mencapai tingkat konsentrasi yang cukup tinggi yang kemudian menghasilkan tenaga psikokinetis.

\section{Interpretasi}

Ada bahasa yang memiliki keanggotaan lambang yang banyak untuk medan makna tertentu, misalnya bahasa Jawa (Pateda, 2001:256). Orang yang mempunyai kompetensi mengenai bahasanya tidak akan salah memilih konstruksi yang benar dan akan memiliki kata yang sesuai dengan pemakaiannya. Mantra yang dilakukan pawang hujan $\mathrm{Ki}$ Ageng Sumari dan Joko Hari Nugroho memiliki arti minta kepada Tuhan yang Mahakuasa agar hujan tidak turun di suatu tempat pada saat tertentu.

Medan makna dalam mantra pawang hujan Ki Ageng Sumari dan Joko Hari Nugroho hanya dapat dimengerti dengan mengetahui latar belakang budaya keduanya dan latar belakang bahasa yang digunakannya. Mereka menggunakan bahasa Jawa dan dalam setiap kata dan kalimat yang memiliki arti khusus. Mantra yang dilafalkan tak hanya berupa deretan bunyi tetapi penuh makna. Tanpa memahami budaya yang melatarbelakangi, mantra ini hanya menjadi deretan kata-kata yang tidak memiliki arti mendalam. < http://endahimawati.blogspot.co.id/2010/1 0/mantra-pawang-hujan.html>

Pengetahuan akan budaya penutur asli akan membuat pemahaman atas bahasa yang digunakan menjadi lengkap. Kelengkapan ini diperlukan supaya tidak terjadi salah persepsi. Mantra yang digunakan oleh dua pawang hujan ini tidak untuk memanggil roh-roh tetapi justru untuk menguatkan diri dan pasrah kepada Tuhan.

Penelitian atas sastra lisan seperti mantra perlu dilakukan karena dari kajiankajian ini akan terlihat budaya Indonesia yang beragam. Kajian linguistik pada mantra juga bisa menepis anggapan bahwa mantra selalu berkonotasi negatif. Bagi sebagian orang Jawa, sepanjang hidupnya selalu ada mantra yang menyertai mulai dari dalam kandungan, lahir, tumbuh, menikah, hingga mati.

\section{Ritual Penangkal Hujan di Indonesia dan Jepang}

\subsection{Ritual Penangkal Hujan di Indonesia} 4.1.1 Ritual di Lombok

Masyarakat Lombok telah menyelenggarakan Ritual Turun Taun "mohon hujan" menjelang musim tanam, dengan iringan lirik berikut: < http://www.sumbawanews.com >

Turun taun léq Gedong Sari (Turun hujan dari Gedong Sari)

Mumbul katon suarga mulia (Semburan hujan laksana sorga mulia)

Langan Dé Sida Allah nurunang sari (Berkah rahmat Tuhan menurunkan kebahagiaan)

Sarin merta sarin sedana... (Sumber kebahagiaan hidup)

\subsubsection{Ritual di Jawa}

Tradisi tolak hujan juga dikenal dalam tradisi Kejawén (Jawa). Permohonan dilakukan dengan mendirikan sapu lidi yang ditusukkan cabai dan bawang merah, diiringi doa berikut: 
Niat ingsun ora ngadekaké sapu biasa (Niat hamba bukan sekedar mendirikan sapu biasa)

Nanging sapu jagat kanggo ngresiki mendhung (Tetapi sapu jagad yang mampu membersihkan mendung)

Udan lan angin saka daérah Semarang (Hujan dan angin di wilayah Semarang)

dibuang menyang Weleri

(Dipindahkan ke daerah Weleri)

sawetara wektu rong ndina (Untuk jangka waktu 2 hari)

Saking kersaning Allah ingkang murbéng jagad (Ini terjadi atas berkah Allah, Penguasa Semesta Alam)

$<$ http://www.pranaindonesia.wordpre ss.com $>$

\subsubsection{Tradisi di Bali}

Dibandingkan dengan budaya etnis Jawa dan Sasak, etnis Bali dikenal paling sering melakukan ritual sejenis. Praktik nerang tolak hujan bahkan dapat ditemukan pada hampir di setiap acara besar di perkotaan atau pedesaan. Nerang dilakukan dengan sarana sajen, rerajahan simbol dan bahasa. Secara empiris, ritual tolak hujan itu dapat ditemukan pada kegiatan keagamaan yang berskala kelompok, banjar, desa, hingga wilayah yang lebih luas. Pada upacara piodalan perayaan pura, pawiwahan pernikahan, pasolahan pementasan, pamelastian penyucian arca, pawintenan penyucian diri, atau acara luar ruangan lainnya, ritual nerang tolak hujan selalu dilaksanakan.

Dalam perkembangannya, nerang bahkan juga dimanfaatkan sebagai proteksi acara nonreligi, seperti pelantikan pejabat, pergelaran seni budaya, pesta olahraga, pembukaan hotel, pembuatan tanggul hingga pengecoran bangunan bertingkat. Sejalan dengan popularitas teks, juru terang atau tukang terang,pawang hujan menjadi label yang disandangkan pada partisipan kunci (Pernyataan Ketua PHDI Bali). < http://www.sumbawanews.com >
Tingginya frekuensi pelaksanaan teks tolak hujan di Bali tampak tidak sejalan dengan pengetahuan publik. Artinya, warga masyarakat yang kerap terlibat dalam teks nerang tolak hujan tetap tidak memiliki pengetahuan yang memadai tentang struktur tuturan yang dilantunkan maupun fungsi simbol-simbol yang digunakan oleh tukang terang. Jadi, perlu ditelusuri pemicu kesenjangan antara keterlibatan fisik dengan logika pengetahuan terhadap teks.

\subsection{Ritual Penangkal Hujan di Jepang}

Di Jepang, untuk menolak hujan mereka mempercayai boneka putih yang digantung di jendela. Boneka itu disebut teru-teru bozu. Ternyata teru teru bozu, seperti juga kepercayaan lainnya di dunia juga memiliki cerita di baliknya. Teru teru bozu sudah digunakan sejak zaman dahulu kala di Jepang sebagai penangkal hujan. Teru teru bōzu adalah boneka tradisional Jepang yang terbuat dari kertas atau kain putih yang digantung di tepi jendela dengan menggunakan benang.

Dari segi bentuk dan pembuatannya, boneka tersebut mirip dengan boneka hantuseperti yang dibuat pada saat Halloween. Jimat ini diyakini memiliki kekuatan ajaib yang mampu mendatangkan cuaca cerah dan menghentikan atau mencegah hujan. Dalam bahasa Jepang, teru adalah kata kerja yang berarti "bersinar" atau "cerah", dan bōzu dapat berarti bhiksu, atau dalam bahasa pergaulan masa kini dapat berarti "kepala botak"; kata itu juga merupakan istilah akrab untuk menyebut bocah lelaki.

Teru teru bōzu menjadi populer selama zaman Edo di antara masyarakat urban, di mana anak-anak membuatnya untuk memohon cuaca baik sehari sebelumnya dan bernyanyi "pendeta cuaca baik, cerahkan cuaca esok hari." Secara tradisonal, jika cuaca berubah cerah, mereka akan digambari mata (bandingkan dengan daruma), sesajen berupa sake suci dituangkan pada mereka, kemudian dihanyutkan di sungai. Di masa kini, anak- 
anak membuat teru-teru-bōzu dari tisu atau kapas dan benang lalu menggantungnya di jendela ketika mengharapkan hari yang cerah, seringkali sebelum hari piknik sekolah. Menggantungnya secara terbalik berarti memohon agar hujan turun. Bahkan satu lagu anak anak dibuat dan dinyanyikan saat membuat Teru Teru Bozu.

http://japansayskutabaru.blogspot.co.id/20 14/01/teru-teru-bozu-boneka-penangkalhujan.html>

\section{Lirik lagu Teru Teru Bozu \\ Teru-teru-bōzu, teru bōzu \\ Ashita tenki ni shite o-kure \\ Itsuka no yume no sora no yō ni \\ Haretara kin no suzu ageyoTeru- teru-bōzu, teru bōzu \\ Ashita tenki ni shite o-kure \\ Watashi no negai wo kiita nara \\ Amai o-sake wo tanto nomashoTeru- \\ teru-bōzu, teru bōzu \\ Ashita tenki ni shite o-kure \\ Sorete mo kumotte naitetara Sonata \\ no kubi wo chon to kiru zo.}

\section{Simpulan}

Dengan studi ini penulis berharap pembaca dapat mengetahui ritual penangkal hujan di beberapa daerah di Indonesia yaitu di daerah Lombok, Jawa, dan Bali serta ritual penangkal hujan di Jepang. Ritual di Indonesia membutuhkan benda atau objek yang harus disediakan yaitu dalam bentuk sesaji, sedangkan di Jepang ritual ini menggunakan boneka putih yang digantung di jendela yang disebut teru-teru bozu. Hal yang menarik dari ritual penangkal hujan ini adalah mantra yang digunakan pawang hujan ketika ingin menghentikan hujan. Mantra itu berbeda-beda antara satu daerah dengan daerah yang lain. Semua keberhasilan pawang hujan ditetukan oleh rasa percaya masyarakat daerah tersebut.

Studi ini masih membutuhkan penelitian lanjutan untuk menjadikannya lebih sempurna. Peneliti berikutnya dapat memanfaatkan hasil penulisan ini sebagai pijakan dan selanjutnya dapat melakukan pengembangan sesuai bidang dan komunitas yang diteliti.

\section{Daftar Pustaka}

Darori, Amin. 2000. Islam dan Kebudayaan Jawa. Yogyakarta: Gama Media.

Endraswara, Suwardi. 2014. Mistik Kejawen. Jakarta: PT Buku Seru.

Harsojo. 1982. Pengantar Ilmu Antropologi. Bandung: Bina Cipta.

Hooykaas, J. 1980. Drawings of Balinese Sorcery. Leiden: E. J. Brill.

Koentjaraningrat. 2002. Pengantar Ilmu Atropologi. Jakarta: Rineka Cipta. 1990.Sejarah Teori Antropologi II. Jakarta : UI Press. Mulyana. 1999. Metodologi Penelitian Kualitatif. Jakarta: Gramedia.

Nawawi, H. Hadari. 1983. Metode Penelitian Deskriptif. Gajah Mada University.

Press. Yogyakarta.

Pateda, Mansoer. 2001. Semantik Leksikal. Jakarta : Rineka Cipta.

Saputra, H.S.P. 2007.Memuja Mantra, SabukMangirdanJaranGoyang

MasyarakatSuku UsingBanyuwangi. Yogyakarta: LKIS.

Sudikan, 2001. Metode Penelitian Kebudayaan. Surabaya: Citra Wacana.

\section{Sumber-sumber dari Internet}

Antar. $2013 . \quad$ Dalam http://www.antaranews.com.

Diunduh pada 9 Desember 2016. Japan.

2014. dalam http://japansayskutabaru.blogspot.co .id/2014/01/teru-teru-bozu-bonekapenangkal-hujan.html. Diunduh pada 9 Desember 2016.

Liputan 6. 2015. Dalam http://regional.liputan6.com/read/24 38216/begini-cara-kerja-pawanghujan-mengendalikan-hujan.

Diunduh pada 9 Desember 2016. 
Mawati, Indah. 2010. Dalam http://endahimawati.blogspot.co.id/2 010/10/mantra-pawang-hujan.html. Diunduh pada 9 Desember 2016.

Sumbawa. 2012.

Dalam

http://www.sumbawanews.com.

Diunduh pada 9 Desember 2016. 